\title{
A ARquitetura E O PROJETO DA PAISAGEM PAULISTA
}

\author{
Rodrigo Queiroz
}

A forma abstrata e construtiva da arquitetura moderna, resultante da síntese desejável entre arte e indústria, é a imagem de sua predisposição à multiplicação, ou seja, de sua irreversível condição urbana. Entretanto, tal condição não diz respeito à sua controversa inserção na cidade histórica, mas à sua existência como componente de uma estrutura espacial unitária, mas extensível: a cidade moderna.

0 artigo de abertura desta edição "Inventar o passado, construir o futuro: São Paulo entre nacionalismos e cosmopolitismos nas primeiras décadas do século 20", de Joana Mello de Carvalho e Silva e Ana Claudia Veiga de Castro, assim como o texto da seção Depoimentos, "Um parque na metrópole de concreto", de Ana Claudia Castilho Barone, abordam justamente essas duas condições distintas da arquitetura, como objeto e como modelo, em ambos os casos ambientada na paisagem e no cenário cultural paulista em períodos definidos pelos seus dois marcos modernizadores mais significativos: a década de 1920 e a Semana de 22; a década de 1950 e o IV Centenário da Cidade de São Paulo.

O texto de Ana Barone consiste na descrição da exposição "Ibirapuera: modernidades sobrepostas"1, que apresenta as ambiguidades inerentes a um processo de modernização descompassado. A arquitetura do conjunto do parque, projetado por Oscar Niemeyer, prenuncia a revisão crítica sobre os excessos cometidos pelo livre agenciamento de uma caligrafia moderna, mas autoral, apresentada pelo mesmo arquiteto no conjunto da Pampulha (1940/1943). Entretanto, na contramão desse processo de simplificação de uma estrutura formal e espacial, a obra pictórica elaborada para ocupar os espaços do Palácio das Artes (OCA) não ultrapassa o limite de um cubismo ameno, no melhor exemplo de um "retorno à ordem", que, no caso brasileiro, vale lembrar, tratase de um retorno a um lugar que, até aquele momento, ainda não havíamos saído: a figuração.
Paralelamente à síntese arquitetura/paisagem, exemplificada pelo conjunto do Ibirapuera, a exposição também apresenta um conjunto significativo de edifícios modernos, nesse caso, inseridos no tecido urbano da região central de São Paulo, assinados por arquitetos como Rino Levi, Vilanova Artigas e o próprio Niemeyer.

$\mathrm{O}$ argumento da arquitetura moderna como elemento constituinte da imagem progressista da metrópole também se faz presente em "Inventar o passado, construir o futuro: São Paulo entre nacionalismos e cosmopolitismos nas primeiras décadas do século 20". Entre um ecletismo belle époque, a retomada de seu passado colonial, e adesão à arquitetura moderna, nas primeiras décadas daquele século, a paisagem urbana da capital paulista reflete o jogo entre correntes estéticas que buscam afirmar-se em uma cidade em acelerado processo de crescimento territorial e demográfico. A busca pela imagem referencial representativa de uma suposta identidade paulista é responsável pela construção de estigmas perpetuados no imaginário do "homem metropolitano", tais como as críticas à subsistência que conduz as vidas do indígena e do caipira.

A eleição de símbolos pretensamente representativos da identidade paulista, como o resgate da arquitetura colonial, defendido por Ricardo Severo e também por Monteiro Lobato, pressupõe a desqualificação de outros estilos, como o ecletismo. Contudo, na opinião de Mário de Andrade, seria a arquitetura moderna a responsável pela constituição de uma possível atualização dessa identidade, desde que resolvido o dilema da "questão nacional e o caráter universal e anônimo da arquitetura moderna".

A adesão à atualidade da arquitetura moderna desdobrará no contraditório esforço para sua nacionalização. Difusor e defensor da "nova arquitetura", o arquiteto russo, radicado no Brasil 
desde 1923, Gregori Warchavchik, com seus artigos e seus projetos residenciais, apontará para a internacionalidade moderna como perspectiva inevitável para a arquitetura nacional.

Warchavchik desvincula a arquitetura moderna do caráter estilístico que justificou as experiências anteriores, definindo-a como uma inteligência promotora do desenvolvimento social pelas vias do urbanismo, da industrialização e da educação. 0 caráter democrático de uma forma livre do supérfluo, ou seja, de sua condição ornamental, associado ao necessário processo industrial de produção de seus novos componentes, na opinião do arquiteto, consiste na direção de uma concepção urbanística aberta, contrária à empoeirada "rua corredor" e, nesse sentido, fundamental como resposta à metrópole em exponencial processo de crescimento.

Segundo a crítica de arquitetura Sophia Telles, "A arquitetura moderna já é urbanismo no momento em que se constitui. Ela supõe a série, o standard, a planificação a partir da perspectiva zero. O Mundo Novo"2. Está no cerne da elaboração da forma moderna, pelo menos em sua vertente construtiva, a resistência em defini-la como objeto de exceção, pois a mola propulsora do projeto parte da perspectiva de sua implantação em escala urbana, resultando em um espaço oposto ao tecido fracionado da cidade histórica. É justamente essa compreensão da forma moderna, como parte de uma totalidade resultante da disposição ordenada de um conjunto delas sobre a superfície, que aproxima, paradoxalmente, o conjunto de Niemeyer no Ibirapuera e as ideias de Warchavchik. Em ambos os casos, a edificação moderna só se justifica se reconhecida como parte integrante de uma totalidade constituída pela relação entre forma e espaço. Separadas por três décadas, essas visões distintas sobre o moderno situam a arquitetura como protagonista de processos de renovação distintos: a ruptura com a tradição, conduzida por uma posição afirmativa, lastreada pela adesão às vanguardas construtivas; e a consolidação da arquitetura moderna como imagem síntese da autonomia cultural não só da cidade de São Paulo, mas do Brasil.
Os temas abordados nos outros 11 artigos que integram a presente edição ilustram a diversidade inerente ao vasto campo do conhecimento que define a arquitetura, o urbanismo e o design.

Em "Por uma epistemologia contemporânea da paisagem: ensaios sobre cinco proposições teóricas", a pesquisadora Aline de Figueirôa Silva realiza um ensaio a partir do livro "Cinq propositions pour une théorie du paysage", organizado por Auguste Berque. Longe de ser definida como um fenômeno físico a priori, a paisagem, segundo os autores do livro analisado por Aline, consiste em um dinâmico fenômeno dialético, diferenciando-a de categorias que aparentemente podem ser confundidas com o sentido de paisagem, tais como: meio ambiente, espaço, lugar e território.

O autor Matteo Santi Cremasco em "Origens do movimento pós-moderno em Minas Gerais", como indica o título do texto, faz uma análise das circunstâncias culturais e econômicas que propiciaram o estabelecimento do movimento pósmoderno na cena da arquitetura mineira a partir da década de 1980. O autor faz um detalhado histórico das relações entre política, economia, a produção arquitetônica e o ensino da arquitetura, do início do regime militar, em 1964, até a promulgação da Constituição de 1988. A curiosa vinculação da arquitetura moderna com o regime militar, associada à abertura para novas ideias, mais flexíveis, sobre os projetos do edifício e da cidade, presentes nas obras de autores como Aldo Rossi e Robert Venturi, faz da cidade de Belo Horizonte o epicentro do movimento pós-moderno no Brasil. Aliás, tratou-se de um movimento tão característico e emblemático no contexto de Minas Gerais, que o termo "pós-moderno mineiro" é praticamente sinônimo da produção dita pós-moderna em território nacional. O autor dedicase à análise de dois projetos dos arquitetos Éolo Maia e Sylvio Emrich de Podestá, ideólogos do movimento, são eles: a Casa Arquiepiscopal de Mariana (1984/ 1987 - em parceria com Maria Josefina de Vasconcelos e a Rainha da Sucata (1985/1992), edifício voltado para Praça da Liberdade, em Belo Horizonte, cuja feição "collage" é a imagem símbolo dessa inclinação ao historicismo compositivo que marcou os projetos desse grupo de arquitetos mineiros. 
"Entre reses e almas: questões sobre urbanização, arquitetura e arte das missões jesuíticas dos sertões das capitanias no Norte", de Esdras Arraes, situa a estrutura urbana das capitanias do Norte, resultante da locação dos aldeamentos missioneiros, como decorrência da complexa relação entre o ofício da catequese jesuítica e a atividade pecuarista.

Em “Errar é urbano. Para uma hodologia de Lisboa", Tiago Mesquita Carvalho apresenta as transformações urbanas e comportamentais em Lisboa após a popularização do uso do automóvel, além de questionar o desenho urbano que privilegia o automóvel na mesma proporção que subjulga as áreas livres e os pedestres.

As autoras Vanessa de Pacheco Melo e Sílvia Leiria Viegas, em "Habitação de iniciativa pública em Luanda e Maputo: modelos de intervenção e impactos socioterritoriais no novo milênio", demonstram que a mera implantação de modelos arquitetônicos distintos, no caso a habitação vertical e de piso único, não resulta em um projeto coerente de urbanização, pois promove o direito à moradia, mas desconsidera o "direito à cidade", ao estruturarem tais conjuntos como bolsões apartados de uma estrutura urbana mínima.

"Acessibilidade e qualidade de vida na habitação de interesse social: avaliação das unidades habitacionais acessíveis do Demhab em Porto Alegre", de Luciane Tabbal, João Carlos Jacottet Piccoli e Daniela Müller de Quevedo, faz uma análise detalhada das condições de acessibilidade das Unidades Habitacionais Acessíveis a Pessoas com Deficiência, projetadas e construídas pelo Departamento Municipal de Habitação, em Porto Alegre. A pesquisa revelou que, apesar de acessíveis, as unidades carecem de alterações no projeto, principalmente nas instalações elétricas e hidrossanitárias.

No artigo "Estação da Luz e Terminal Barra Funda: integração com a rede de metrô", o autor, Bruno Ribeiro Fernandes, discorre sobre as mudanças ocorridas nas estações de trem da Luz e da Barra Funda após a interligação de ambas à malha metroviária. As diferenças entre a conexão subterrânea, na Luz, e aérea, na Barra Funda, são objeto de crítica do autor, que pondera entre a facilidade da construção da conexão aérea, em mezanino, e a dificuldade da construção em túnel, mas que preserva o protagonismo da gare original da Estação da Luz.

"Sobre dimensões fractais de ambientes construídos e naturais", de Natália Naoumova, Andrei Bourchtein e Lioudmila Bourchtein, apresenta os estudos fractais como instrumentos para a preservação da ambiência em sítios históricos em projetos de revitalização, assim como uma "ferramenta criativa" para a "criação da dinâmica espacial" em projetos que envolvam a relação entre a construção e extensas paisagens naturais.

Em "Ensaio sobre a tipografia brasileira", Luiz Fukushiro faz uma crítica à associação da tipografia vernacular a uma suposta tipografia brasileira, assim como discorre sobre a interessante relação entre a tipografia e a construção das palavras na língua portuguesa.

"lluminação e saúde humana: estado da arte em dispositivos de medição de luz no nível dos olhos", de Maíra Vieira Dias, Paulo Sergio Scarazzato, Edson Moschim e Felipe Rudge Barbosa, apresenta estudos sobre a intensidade luminosa próxima à região ocular, suas técnicas de medição e aponta para a iluminação adequada como um fator de melhoria da qualidade de vida.

"Investigações sobre as limitações dos sistemas de reprodução fotográfica fine art: comparação de rendering intents colométrico e percentual", de Bruno Mortara, avalia a reprodução fotográfica de alta qualidade e seu grau de fidelidade em relação ao objeto real ou ao arquivo de imagem digital.

A seção conferências conta com o texto da professora Maria Lucia Bressan Pinheiro, referente à exposição "Raul Lino: cem anos depois" e ao "Colóquio Internacional Arts \& Crafts - repercussões em Portugal e no Brasil", ambos realizados na Vila Penteado, sede do Programa de Pós-Graduação da FAUUSP, entre os meses de abril e maio de 2014.

Já a seção Núcleos e Laboratórios de pesquisa e serviços de apoio da FAUUSP, traz "Os kombinate e a construção pré-fabricada de moradias na Alemanha Oriental", versão em língua portuguesa de três textos de autoria dos professores Joachim Stahr ("A arquitetura habitacional e os mecanismos de dominação na Alemanha Oriental”) e Christine 
Hannemann ("A organização da construção civil na Alemanha Oriental" e "A família nuclear socialista"), apresentados aqui por Yvonne Mautner e Cíntia Alves. Trata-se de uma detalhada análise da política habitacional, dos projetos arquitetônicos e das estratégias de implantação dos conjuntos habitacionais na extinta Alemanha Oriental entre as décadas de 1950 e 1970.

Na seção resenhas, a professora Mônica Junqueira de Camargo faz uma precisa análise do livro "Vilanova Artigas: habitação e cidade na modernização brasileira", dos professores Leandro Medrano e Luiz Recamán. Outros dois livros também foram resenhados nesta edição, são eles: "Lugares de produção: arquitetura, paisagens e patrimônio", organizado por Telma de Barros Correia e Maria Angela P. C. S. Bortolucci, com resenha de Maria Lucia Bressan Pinheiro, e "Preservação e restauro urbano: intervenções em sítios históricos industriais", de Manoela R. Rufinoni, resenhado pelo professor Júlio Roberto Katinsky.

\section{Notas}

1 Exposição em cartaz no Pavilhão Lucas Nogueira Garcez - OCA, de 04 de setembro de 2014 a 29 de março de 2015, cuja curadoria dividi com a professora. Ana Claudia Castilho Barone.

2 TELLES, Sophia. A arquitetura modernista: um espaço sem lugar. Arte Brasileira Contemporânea. Caderno de Textos, n.03, Rio de Janeiro, Funarte/Instituto Nacional de Artes Plásticas, 1983.

Boa leitura.

Rodrigo Queiroz

Editor-chefe

roqueiro@usp.br 